\title{
A CATEGORIA DA MEDIAÇÃO: CONTRIBUIÇÕES PARA A EDUCAÇÃO ESCOLAR E PARA O TRABALHO DO PROFESSOR ${ }^{1}$
}

\author{
Carina Alves da Silva DARCOLETO ${ }^{2}$
}

\section{Resumo}

O presente texto tem o objetivo de tratar a educação escolar como uma fundamental mediação entre o homem (singular) e o conhecimento produzido e acumulado pela humanidade historicamente (geral); concebendo-a na sua relação de interdependência com a totalidade da sociedade, o que será elucidado com o exame da categoria ontológica da mediação, a qual permite compreender o homem inserido no contexto da sociedade capitalista, as possibilidades e os limites que dela derivam, de modo geral, e as questões próprias à educação escolar, em particular. Para tanto, recorrer-se-á à análise das mediações apresentada por István Mészáros, em suas obras "Marx: a teoria da alienação" (1981) e "Para além do capital: rumo a uma teoria da transição" (2002), a qual fornece a chave para se pensar em uma educação escolar comprometida com a transformação social.

\section{Introdução}

Neste texto, pretende-se abordar a educação escolar na sua relação dialética com a sociedade, compreendendo-a como um complexo social que não prescinde, jamais, das outras instâncias da totalidade social, ao mesmo tempo em que possui sua especificidade e particularidade. Esta abordagem é possível a partir da elucidação da categoria ontológica da mediação, a qual permite compreender o homem inserido no sistema capitalista, suas possibilidades e seus limites, de modo geral, e, em particular, as questões próprias à educação.

A análise da mediação será feita a partir dos estudos do filósofo húngaro contemporâneo István Mészáros, uma vez que este autor, ao atualizar o pensamento e a ontologia marxiana, contribui imensamente para o tratamento da educação escolar enquanto parte do sistema capitalista de reprodução do metabolismo social, possibilitando, ao mesmo tempo, sua abordagem histórico-concreta, a qual mostra os seus limites, bem como uma apreensão ontológica que afirma as suas possibilidades imanentes.

Considerando-se a extensa e complexa produção do autor, valer-se-á do exame da categoria da mediação presente em suas obras "Marx: a teoria da alienação" (1981) e "Para além do capital: rumo a uma teoria da transição" (2002), apontando aqueles

\footnotetext{
${ }^{1}$ Este artigo é parte do desenvolvimento de nosso projeto de mestrado, em andamento, financiado pela CAPES.

${ }^{2}$ UNESP - FCL - Araraquara/SP/Brasil: mestranda do PPG Educação Escolar e-mail: carinadarcoleto@yahoo.com.br
} 
que se avalia serem os principais aspectos de sua abordagem para a compreensão da referida categoria. Nessa medida, serão feitas pontuações a respeito do trabalho exaustivo de Mészáros sobre o sistema do capital, mais especificamente na sua forma capitalista, mostrando suas implicações para a manutenção das mediações de segunda ordem (alienadas e alienantes). Em seguida, serão tecidas algumas ponderações a respeito da importância da educação escolar no que se refere às possibilidades de transcendência das mediações alienadas.

\section{Capital e capitalismo: a especificidade das mediações de segunda ordem}

A compreensão da sociedade contemporânea (e da educação escolar) e dos problemas que ela enfrenta e/ou deve enfrentar implica em conhecer e reconhecer as mazelas do sistema capitalista, com as suas mais variadas formas de mediações alienadas. Entretanto, chegar a tal reconhecimento não é fácil, pois, por mais que os problemas estejam tão à vista, a alienação (material e também espiritual) torna-se cada vez mais perversa, "varrendo" os problemas "para baixo do tapete". Nesta perspectiva, é preciso que se recorra às diferenças entre o capital e o capitalismo, tese central que rege toda a discussão apresentada por István Mészáros em sua obra "Para Além do Capital" $(2002)^{3}$, na qual o seu ponto de partida é a análise do capital e de suas implicações para a humanidade.

Nessa obra, Mészáros afirma que é imprescindível que se compreenda a aludida distinção entre capital e capitalismo, visto que muitos pensadores acreditam que a ruptura com o sistema capitalista seria suficiente para se atingir uma sociedade socialista, humanizada, situando o problema da alienação como próprio ao capitalismo. Segundo o filósofo húngaro, a ruptura com o capitalismo não levaria à mudança radical da sociedade, pois o que é preciso ser destruído, de fato, é o capital, o qual antecede o capitalismo e é também posterior a ele; sendo compreendido como "o regulador sociometabólico do processo de reprodução material que, em última análise, determina não somente a dimensão política, mas muito mais além dela" (MÉSZÁROS, 2002, p. 29).

Enfaticamente, o autor defende que o capitalismo é apenas uma forma de realização do capital, por sinal a força histórica de realização desse capital que reuniu as formas mais plenas e perfeitas para seu desenvolvimento. Nesse sentido, salienta que é no capitalismo que o Sistema Sociometabólico do Capital ${ }^{4}$ - que tem como núcleo fundante, nesse contexto histórico, a relação entre capital, trabalho e Estado - ganha maior impulso. Em outras formas de organização social, como nas sociedades feudais,

\footnotetext{
3 István Mészáros se dedicou aproximadamente 25 anos para elaborar essa obra. Para este estudo, utilizou-se a tradução brasileira publicada pela Boitempo Editorial, em 2002, quando tal obra chega pela primeira vez ao Brasil, em português. "A tradução foi feita a partir da edição original inglesa, de 1995 (Beyond Capital - Towards a Theory of Transition, Merlin Press)" (JINKINGS, I In: MÉSZÁROS, 2002, p. 13; nota do editor).

4 “o sistema de sociometabolismo do capital é poderoso e abrangente, tendo seu núcleo constitutivo formado pelo tripé capital, trabalho e Estado, sendo que estas três dimensões fundamentais do sistema são materialmente constituídas e inter-relacionadas e é impossível superar o capital sem a eliminação do conjunto dos elementos que compreende este sistema”. (ANTUNES, R. In: MÉSZÁROS, 2002, p. 16).
} 
por exemplo, não existia esse núcleo. Havia tanto o capital quanto o trabalho, mas suas formas de manifestação eram diferentes das existentes na sociedade moderna.

Com a dissolução das formas de funcionamento da sociedade feudal (trabalho servil, capital existente na forma de troca de mercadorias), as forças do capital vão se solidificando. Começa a surgir um capital diferente do capital comercial antes existente. É nesse momento histórico de surgimento do capital mercantil que se pode conceber uma forma mais plena do Sistema Sociometabólico do Capital. A partir daí o capital inicia sua fase mais completa de desenvolvimento, a qual está posta em sua forma industrial, na qual tem-se o predomínio da produção de mercadorias através do uso de máquinas, bem como o predomínio do lucro. Segundo Mészáros (2002),

\begin{abstract}
As unidades básicas das formas antigas de controle sociometabólico eram caracterizadas por um grau elevado de auto-suficiência no relacionamento entre a produção material e seu controle. Isto se aplica não apenas às comunidades tribais primitivas, mas também à economia doméstica das antigas sociedades escravistas e ao sistema feudal da Idade Média. Quando esta auto-suficiência se quebra e progressivamente dá lugar a conexões metabólicas/reprodutivas mais amplas, já estamos testemunhando o vitorioso avanço do modo de controle do capital, trazendo consigo, no devido tempo, também a difusão universal da alienação e da reificação. (MÉSZÁROS, 2002, p. 101).
\end{abstract}

A alienação e a reificação de que fala Mészáros (2002), logo no final da citação acima, estão intrinsecamente relacionadas ao modo como se processa o Sistema Sociometabólico do Capital, que, para o autor, desenvolve-se por meio das personificações do trabalho e do capital, personificações estas já apontadas por Karl Marx, pela primeira vez, nos Grundrisse. É sabido que cada forma histórica tem seu modo próprio de sociabilidade e, portanto, personificações adequadas a este mesmo modo. No caso da sociedade capitalista, não existe estabilidade nas relações que o homem estabelece, tanto com a natureza quanto com seus pares, a única certeza, necessidade e persistência está na produção de mercadorias e no lucro. Analisando o potencial das personificações do capital, Mészáros adverte:

Sob o sistema do capital estruturado de maneira antagonista, a verdadeira questão é a seguinte: qual é a classe dos indivíduos que realmente produzem a 'riqueza da nação' e qual a que se apropria dos benefícios dessa produção; ou, em termos mais precisos, que classe de indivíduos deve ser confinada à função subordinada da execução e que indivíduos particulares exercem a função de controle - como 'personificações do capital', na expressão de Marx. (MÉSZÁROS, 2002, p. 68).

Essas personificações alienam o homem da sua condição humana, uma vez que ele é concebido apenas como um "meio" (pela sua função de trabalhador) para se atingir os interesses do capital, os quais se sobrepõem ao ser social, que se descaracteriza enquanto tal.

Sendo assim, o trabalho, que é a categoria, de acordo com Marx, por excelência, capaz de propiciar o pleno desenvolvimento do homem, torna-se, neste cenário do sistema capitalista, um trabalho intensamente alienado e alienante, visto o próprio homem não entender o sentido daquilo que produz e não perceber o sentido da sua atividade dentro do processo da produção. Nas palavras de Mészáros, 
O trabalho, que deveria ser uma propriedade interna, ativa, do homem, em conseqüência da alienação capitalista se torna exterior ao trabalhador ('o trabalho é exterior ao trabalhador, isto é, não pertence ao seu ser essencial; [...] O trabalhador, portanto, só se sente ele mesmo fora de seu trabalho, e em seu trabalho sente-se fora de si mesmo'). (...) A alienação transforma a atividade espontânea no "trabalho forçado", uma atividade que é um simples meio de obter fins essencialmente animais (comer, beber, procriar), e com isso 'o que é animal se torna humano e o que é humano se torna animal'. (MÉSZÁROS, 1981, p. 141).

Se o trabalho é, ontologicamente, necessário para o desenvolvimento do homem, e com o sistema tal como está posto ele não consegue cumprir esta função, fica claro que alternativas são imprescindíveis para se atingi-lo como, de fato, ele pode ser realizado pelo ser humano. E quais alternativas seriam necessárias?

Para responder a esta indagação é preciso compreender que o trabalho que o homem está realizando perdeu a sua característica mais importante, conforme pensava Marx: a de mediação de primeira ordem. De acordo com Mészáros, em sua obra "Marx: teoria da alienação" (1981), a mediação de primeira ordem seria a única forma possível de o homem se relacionar com a natureza e com o próprio homem, transformando esta natureza e construindo uma "segunda natureza", ou seja, a sociedade, de modo significativo e positivo. Em outras palavras, a mediação de primeira ordem permite ao homem, através de sua atividade produtiva - que proporciona com que ele transforme a natureza e, como parte dela, também se modifique -, compreender o mundo em que vive e entender o seu papel como agente transformador da história.

No Sistema Sociometabólico do Capital, o trabalho, que para Marx é a automediação fundamental entre natureza-natureza (considerando-se a totalidade do homem e tendo-se este como parte da natureza ele também é natureza), homemnatureza e homem-homem, passa a ser, na realidade, uma mediação de segunda ordem. Por que uma mediação de segunda ordem? Porque, neste sistema, as mediações de primeira ordem são interrompidas, dando lugar às mediações de segunda ordem, as quais privam o homem das suas possibilidades de desenvolvimento e, portanto, da humanização que lhe é imanente, mas que só se realizará de acordo com condições históricas favoráveis. Segundo Mészáros,

As mediações de segunda ordem do capital - ou seja, os meios alienados de produção e suas 'personificações'; o dinheiro; a produção para troca; as variedades da formação do Estado pelo capital em seu contexto global; o mercado mundial - sobrepõem-se, na própria realidade, à atividade produtiva essencial dos indivíduos sociais e na mediação primária entre eles. (MÉSZÁROS, 2002, p. 71). ${ }^{5}$

Com a preponderância das mediações de segunda ordem em detrimento das mediações de primeira ordem, realidade indiscutível do sistema do capital, o homem vai se distanciando da sua própria condição humana, privando-se do acesso aos produtos que ele mesmo produziu, em particular, e, especialmente e de modo mais amplo, das conquistas objetivas da humanidade. Desse modo, as relações que o homem estabelece, seja no seu trabalho e/ou nas suas relações com os seus semelhantes, tornam-se cada vez mais desprovidas de sentido para a sua vida.

\footnotetext{
${ }^{5}$ Grifos da autora.
} 


\title{
A alienação no sistema capitalista e suas conseqüências: alguns apontamentos
}

\author{
"toda a chamada história do mundo \\ nada mais é do que a autocriação do \\ homem através do trabalho humano, \\ nada mais é do que o vir-a-ser da \\ natureza para o homem”. Karl Marx.
}

A problemática do capital, trabalhada por Mészáros (2002) na esteira do pensamento marxiano, implica na alienação do homem em relação ao seu trabalho, à própria natureza e a si mesmo. Isto porque, no sistema capitalista, o ser humano é tratado como coisa, e visto como produto, ora na posição de trabalhar em prol da reprodução do sistema, ora como consumidor do mesmo. Nesse sentido,

\begin{abstract}
a alienação humana foi realizada pela transformação de tudo em 'objetos alienáveis, vendáveis, em escravos da necessidade e traficantes egoístas. A venda é a prática da alienação. (...) A alienação se caracteriza, portanto, pela extensão universal da 'vendabilidade' (isto é, a transformação de tudo em mercadoria); pela conversão dos seres humanos em 'coisas', de modo que possam aparecer como mercadorias no mercado (em outras palavras, a reificação das relações humanas); e pela fragmentação do corpo social em 'indivíduos isolados', que visam aos seus objetivos limitados, particularistas, 'em servidão à necessidade egoísta', fazendo de seu egoísmo uma virtude em seu culto da privacidade. (MÉSZÁROS, 1981, p. 36-37).
\end{abstract}

Nota-se, então, que num sistema em que o homem é tratado como mero "objeto" para suprir as necessidades criadas pela lógica imposta por tal sistema, suas características próprias e que, portanto, deveriam ser primadas, passam a ser relegadas. Nessa direção, Mészáros apresenta uma questão ontológica de incontestável importância, a saber: "o que está de acordo com a 'natureza humana' e o que constitui 'alienação' da 'essência humana'?” (MÉSZÁROS, 1981, p. 40).

O trabalho, dentro da perspectiva marxiana, é a categoria que possibilita ao ser humano desenvolver sua natureza e potencializá-la. Mészáros coloca que nos "Manuscritos Econômico-Filosóficos de 1844", Marx tem a preocupação de enfatizar que

o homem, parte específica da natureza (isto é, um ser com necessidades físicas historicamente anteriores a todas as outras), precisa produzir a fim de se manter, a fim de satisfazer suas necessidades. Mas só pode satisfazer essas necessidades primitivas criando necessariamente, no curso de sua atividade produtiva, uma complexa hierarquia de necessidades não-físicas, que assim se tornam condições igualmente necessárias à satisfação de suas necessidades físicas originais. As atividades e necessidades humanas de tipo 'espiritual' têm, assim, sua base ontológica na esfera da produção material como expressões específicas de um intercâmbio entre o homem e a natureza, mediado de formas e maneiras complexas. (MÉSZÁROS, 1981, p. 75-76). 
A partir da afirmação acima, fica claro que o trabalho, para superar a alienação, deve ser uma atividade que humanize o homem e esteja relacionada à satisfação de suas necessidades essenciais. Assim sendo, o trabalho, tal como é realizado no sistema capitalista, não permite ao homem essa condição, mas, ao contrário, sujeita o homem a mais brutal alienação. Segundo Mészáros (1981),

\begin{abstract}
A atividade produtiva na forma dominada pelo isolamento capitalista quando 'os homens produzem como átomos dispersos, sem consciência de sua espécie' - não pode realizar adequadamente a função de mediação entre o homem e a natureza, porque 'reifica' (coisifica) o homem e suas relações e o reduz ao estado de um animal natural. Em lugar da 'consciência da espécie', encontramos o culto da privacidade e uma idealização do indivíduo abstrato. Assim, identificando a essência humana com a mera individualidade, a natureza biológica do homem é confundida com sua natureza propriamente dita. A mera individualidade exige apenas meios para a subsistência, mas não formas especificamente humanas - humanamente naturais e naturalmente humanas, isto é, sociais - de auto-realização; formas que são manifestações adequadas da atividade vital de um (...) 'ser genérico'. (p. 76-77).
\end{abstract}

Constata-se que a atividade produtiva sempre é alienada quando se aparta do modo adequado ${ }^{6}$ de mediar as relações entre o homem e a natureza, ou seja, a relação sujeito-objeto, levando este sujeito (o homem) a ser reabsorvido pela natureza, tornando-se o homem, pois, distante da sua condição de ser humano 'genérico'.

Marx critica e protesta contra a alienação da atividade produtiva e a reificação do homem tão dominantes no sistema capitalista. Nesse sentido, de acordo com Mészáros, aquele não é defensor do retorno do homem à "natureza" e às suas necessidades primeiras, voltando-se para a questão da "plena realização da natureza do homem", o que só é possível através de uma atividade humana automediadora. (MÉSZÁROS, 1981). No tocante à automediação, Mészáros esclarece:

\begin{abstract}
A relação entre o homem e a natureza é 'automediadora' num duplo sentido. Primeiro, porque é a natureza que propicia a mediação entre si mesma e o homem; segundo, porque a própria atividade mediadora é apenas um atributo do homem, localizado numa parte específica da natureza. Assim, na atividade produtiva, sob o primeiro desses dois aspectos ontológicos, a natureza faz a mediação entre si mesma e a natureza; e, sob o segundo aspecto ontológico - em virtude de ser a atividade produtiva inerentemente social - o homem faz a mediação entre si mesmo e os demais homens. (MÉSZÁROS, 1981, p. 77-78).
\end{abstract}

A atividade humana automediadora nada mais é que a chamada "mediação de primeira ordem", ou seja, a mediação necessária para que o homem seja capaz de transformar beneficamente a natureza para seus fins próprios, fins estes que devem contemplar as necessidades sociais da humanidade como um todo. Assim, fica evidente o valor da epígrafe colocada anteriormente: "toda a chamada história do mundo nada mais é do que a autocriação do homem através do trabalho humano, nada mais é que o vir-a-ser da natureza para o homem".

\footnotetext{
${ }^{6}$ A expressão "modo adequado" é usada no sentido de que o trabalho deve ser uma mediação que humanize o homem, aliás, é ele a mediação fundante do ser social e a mediação que funda todas as outras mediações que o homem estabelece com a natureza e com os seus pares.
} 
Portanto, o homem é o único ser capaz de transformar a natureza, criando, como já mencionado, a sua "segunda natureza", que é a sociedade. Entretanto, essa transformação pode ser, ou não, positiva, pode ou não elevar o homem ao seu potencial máximo. No caso da sociedade capitalista, na qual o homem é coisificado, devido à supremacia das mediações de segunda ordem (alienadas e alienantes), as transformações que a natureza sofre por parte do homem chegam a ser destrutivas e até mesmo prejudiciais à própria humanidade. Atento a este problema, Mészáros aponta que Marx analisa a direção da história humana em termos da

imanência do desenvolvimento humano (...), ou seja, como a realização da 'essência humana', do elemento 'especificamente humano', da 'universalidade e liberdade do homem' etc, através do 'estabelecimento do homem por si mesmo, pela atividade prática' (...). O homem, como o 'ser automediador da natureza', não pode deixar de desenvolver - através da dialética objetiva, crescentemente complexa, das necessidades e objetivos humanos (e de acordo com as leis objetivas mais fundamentais da ontologia) - seu próprio papel mediador ativo. (MÉSZÁROS, 1981, p. 106-07).

\title{
Educação escolar: limites e possibilidades
}

\begin{abstract}
"os sentidos humanos não podem ser considerados como simplesmente dados pela natureza. $O$ que é especificamente humano, neles, é a criação deles pelo próprio homem. À medida que a natureza se torna humanizada - mostrando as marcas da atividade humana - os sentidos, relacionados com os objetos cada vez mais humanamente configurados, tornam-se especificamente humanos $e$ cada vez mais refinados." Mészáros.
\end{abstract}

A partir da epígrafe, nota-se que, se os sentidos humanos só se tornam, de fato, humanos quando a natureza vai se tornando humanizada, ou, em outros termos, quando o homem, em relação com a natureza e com os próprios homens, cria a sociedade, a educação é propriedade humana indispensável dentro desse processo. Diante disso, neste momento, tratar-se-á, ainda que sumariamente, dessa questão.

Ao falar sobre a crise atual da educação, Mészáros (1981) concebe que

Nenhuma sociedade pode perdurar sem seu sistema de educação próprio. Mencionar apenas os mecanismos de produção e troca para explicar o funcionamento real da sociedade capitalista é procedimento inadequado. As sociedades existem através dos atos dos indivíduos, que buscam realizar seus próprios fins. Em conseqüência, a questão crucial, para qualquer sociedade, é a reprodução bem-sucedida desses indivíduos, cujos 'fins próprios' não negam as potencialidades do sistema de produção 
predominante. É essa a extensão real do problema educacional: a 'educação formal' é apenas um pequeno segmento dele. (MÉSZÁROS, 1981, p. 260).

Embora Mészáros, ao salientar a importância da educação para a construção e transformação da sociedade, conceba a educação formal (entendida, neste contexto, como aquela realizada pela instituição escolar) como apenas um "pequeno segmento" diante de toda a extensão da educação, de modo geral, pretende-se, aqui, acentuar a relevância da educação escolar para a formação e desenvolvimento do homem, colocando a mediação (de primeira ordem) como a categoria essencial para a relação entre ensino e aprendizagem, bem como para corroborar o processo de luta (não se pode perder de vista, é claro, os limites da educação escolar, que é apenas uma parte da totalidade social) pela transformação dessa sociedade capitalista.

Isto posto, traz-se a discussão da mediação no âmbito da relação ensinoaprendizagem que deve ser estabelecida na e pela escola. Nessa relação, o professor é imprescindível, uma vez que o seu conhecimento e a sua consciência a respeito desse processo de mediação, bem como a sua ação para garantir a apropriação de parte do conhecimento humano pelos seus alunos possibilitarão, com maior força, a necessária mediação entre o ensino e a aprendizagem e entre o professor e o aluno.

Sabendo-se que o professor e o aluno estão em pólos diferentes do processo de ensino e aprendizagem, bem como que esta difere daquele, embora esses pólos estejam diretamente e dialeticamente relacionados, é fundamental entender que o ensino e a aprendizagem ocorrem por meio da mediação.

O termo mediação "na filosofia de G.W. F. Hegel, diz respeito à relação entre o imediato e o mediato. (...) Ela estabelece a ligação entre o imediato e o mediato" (ALMEIDA, 1997, p. 58).

Para Hegel, como afirmado por Almeida, a mediação é a relação entre o imediato e o mediato. Na concepção de Marx, esta relação ocorre entre a natureza e o ser humano, na qual a natureza é o imediato e o homem é o mediato. Como o próprio Mészáros $(1981,2002)$ coloca, a relação entre a natureza e o homem é mediada, de acordo com Marx, pelo trabalho.

Sendo assim, em termos da relação ensino-aprendizagem, é fundamental que o professor realize a sua tarefa, de transmissão de parte dos conhecimentos produzidos e acumulados pela humanidade ao longo da história - isso não pode ser perdido de vista -, tendo como ponto de partida de sua atividade docente as experiências de seus alunos, que se manifestam na forma imediata. Com isso não se quer dizer que o professor se apropriará desse imediato dos alunos, até mesmo porque seria impossível consegui-lo, mas pretende-se afirmar que, na relação professor-aluno, o imediato dos aprendizes se manifesta o tempo todo, cabendo, ao professor, a tarefa de buscar transcendê-lo.

Nesse tocante é muito importante que se tome cuidado para não realizar um trabalho educativo alienado e alienante. Essa ressalva se coloca, simplesmente, porque muitos profissionais da educação confundem o ensinar com ficar "circundando" a "realidade" dos alunos. O que se propõe, na perspectiva da mediação dialética, é que o professor reconheça a realidade e as manifestações imediatas de seus alunos, para, assim, levá-los à superação dessa condição. Quando a experiência imediata dos alunos - 
advinda da sua realidade - é superada, transformando-se em conhecimento (mediato), não significa que aquele imediato seja suprimido, visto ele estar relacionado à realidade vivida pelos estudantes; ao contrário, ele permanece no conhecimento mediato, tal como este está no imediato, mas ambos são, agora, diferentes, uma vez que houve a superação.

Nesse processo de mediação, a prática social de ambos - aluno e professor também se modifica, pois, uma vez transformados e sendo eles parte da sociedade, sua totalidade também é alterada qualitativamente. Entendida nessa dimensão, "a educação, portanto, não transforma de modo direto e imediato e sim de modo indireto e mediato, isto é, agindo sobre os sujeitos da prática" (SAVIANI, 2003, p. 73).

Dito de outra forma, quando essa mediação entre o ensino e a aprendizagem ocorre, as mediações de segunda ordem (alienantes, que impedem que a mediação primária ocorra) são superadas (ainda que, inicialmente, no plano da consciência) e o conhecimento é apropriado pelo aluno. Quando defende-se que a escola tem um papel fundamental na formação dos alunos e que, desta forma, pode colaborar para a mudança da sociedade, não se está colocando o problema da alienação como uma causa de consciência; ao contrário, compreende-se que a alienação é objetiva, que emana da realidade material, mas que também existe no aspecto subjetivo, como resultado da própria dimensão objetiva. Em consonância com Marx e Mészáros, a transformação não é um ato mental, uma questão de consciência; ao contrário, ela deve partir da realidade; o que não significa desconsiderar a importância da consciência (como reflexo da realidade material), na sua relação dialética e de mediação com o plano concreto da vida, para o despertar da necessidade da mudança, que nunca foi tão premente como nos dias atuais. Conforme Marx:

É certo que a arma da crítica não pode substituir a crítica das armas, que o poder material tem de ser derrubado pelo poder material, mas a teoria converte-se em força material quando penetra nas massas. A teoria é capaz de se apossar das massas ao demonstrar-se ad hominem, e demonstra-se ad hominem logo que se torna radical. Ser radical é agarrar as coisas pela raiz. Mas, para o homem, a raiz é o próprio homem. (MARX, 2005, p. 151).

Quando Marx coloca que a "teoria converte-se em força material quando penetra nas massas", faz-se a leitura de que a escola também pode se converter em força material se assegurar a apropriação de conhecimentos pelos alunos (cabe reafirmar que se sabe dos limites da escola, como instituição da ordem capitalista, para trabalhar contra os ditames do capital), por meio da sua transmissão. Deste modo a consciência se torna essencial, pois o homem sente a alienação, vive dia após dia a condição de alienado, mas muitas vezes (se não sempre) naturaliza os problemas que vive, acreditando que a sociedade é e sempre será assim - discurso amplamente difundido pelos apologistas do capital. Apreender que a alienação é histórica e que, por isto, pode ser superada certamente é um passo importante (ainda que não o decisivo) na luta pela mudança radical da sociedade.

\section{Considerações Finais}


O trabalho apresentado, ainda que com os limites inerentes a um artigo, mostra o caráter ontológico do pensamento de István Mészáros e suas contribuições para a elucidação da categoria da mediação como imprescindível para a compreensão das relações sociais, bem como as suas possibilidades para o tratamento da educação escolar.

A abordagem da educação, na sua relação dialética com a totalidade das relações humanas histórico-sociais, revela os limites da educação escolar no cenário da sociedade capitalista. Todavia, por ser a escola parte da sociedade, ao mesmo tempo em que ela afirma esta sociedade, nega-a; daí se compreender, de acordo com Saviani (2003), que a educação não transforma a prática social de modo direto, mas ela pode contribuir, ainda que com limites, para a sua mudança. Assim, fica a aposta em uma educação escolar capaz de propiciar a fecunda mediação entre natureza-homem e homem-homem.

\section{Referências Bibliográficas}

ALMEIDA, J. L. V. (1997). Educadores de Rua do Estado de São Paulo: as representações que informam a sua prática educativa. Tese de doutorado. São Paulo: Universidade de São Paulo (USP), Faculdade de Educação (FE).

ANTUNES, R. (2002). Apresentação. In: MÉSZÁROS, I. Para Além do Capital: rumo a uma teoria da transição. São Paulo/SP: Boitempo (Editora da Unicamp).

JINKINGS, I. (2002). Nota do Editor. In: MÉSZÁROS, I. Para Além do Capital: rumo a uma teoria da transição. São Paulo/SP: Boitempo (Editora da Unicamp).

MARX, K. (2005). Crítica da filosofia do direito de Hegel - Introdução. São Paulo/SP: Boitempo (Editora da Unicamp).

MÉSZÁROS, I. (1981). Marx: A Teoria da Alienação. Rio de Janeiro/RJ: Zahar.

MÉSZÁros, I. (2002) Para Além do Capital: rumo a uma teoria da transição. São Paulo/SP: Boitempo (Editora da Unicamp).

SAVIANI, D. (2003). Escola e Democracia: teorias da educação, curvatura da vara, onze teses sobre a educação política. Campinas/SP: Autores Associados, $36^{\mathrm{a}}$ ed. 